\title{
Trans-orbital orbitocranial penetrating injury by pointed iron rod
}

\author{
Vinod Kumar Tewari, Ram Shringar Dubey ${ }^{1}$, Gyan Chand Dubey ${ }^{2}$ \\ Department of Neurosurgery, ${ }^{1}$ Surgery, ${ }^{2}$ Opthalmology, Ram Manohar Lohia Hospital, Lucknow, Uttar Pradesh, India
}

\section{ABSTRACT}

Trans-orbital orbitocranial penetrating injury (TOPI) by a foreign body is an extremely rare compound head injury having a potential to cause major morbidity and mortality. Preoperative radiological imaging by CT scan is very important for operative guidance, but in remote area where CT scan is not available, the patient is generally referred to tertiary level. Here we present a case which was dealt successfully without CT scan, only on the basis of stable clinical status and X-rays. We present a case of a 35-year-old man who had an accidental injury (fall from height) by rod. Immediate X-ray (anteroposterior and lateral views) revealed that the pointed end of the foreign body (rod) was inside the ipsilateral anterior fossa via basifrontal bone up to frontal vertex, not crossing the midline. CT scan was not available and his vitals with GCS were normal (15/15). He was operated with the help of an ophthalmic surgeon by right frontotemporal craniotomy. The patient was discharged on $10^{\text {th }}$ day without any neurological deficit except restricted right eyeball movement to superolateral and ptosis. The restricted eyeball movements recovered after third month of follow up with remnant ptosis for 2 years. This case highlights an unusual case, direct visualization and repair of brain structures with higher antibiotics can save the life even in remote areas where CT scan is still not available only on the basis of stable GCS and X-rays.

Key words: Metal bar, multispeaiciality approach, non availability of computed tomography scan, transorbital orbitocranial penetrating injury, trans-orbital penetrating head injury

\section{Introduction}

Trans-orbital orbitocranial penetrating injury (TOPI) by foreign body is an extremely rare $(0.4 \%$ of all head injuries) compound head injury. ${ }^{[1,2]}$ These injuries cause serious orbital injury but, if the foreign body bypasses the ocular globe the orbit is saved. A wound in which the projectile material breaches the cranium but does not exit is described technically as penetrating, and an injury in which the projectile passes entirely though the head, leaving both entrance and exit wounds, is described as perforating. ${ }^{[3]}$ Non-missile TOPI are usually caused by metallic knives or sharp cutting objects but the list may include materials of plant origin, sharpened wooden sticks, ice picks, or metallic material like screw drivers,

\begin{tabular}{|l|l|}
\hline \multicolumn{2}{|c|}{ Access this article online } \\
\hline Quick Response Code: & Website: \\
\hline & www.ruralneuropractice.com \\
\cline { 2 - 3 } & \\
\hline
\end{tabular}

nails, spikes, fishing harpoons, scissors, sewing needles, iron rods, arrows, synthetic plastic material, ceramic or glass or even naturally occurring stone. ${ }^{[4-6]}$ CT scan is mandatory for every case and if the foreign body traverses the whole brain, it is operated ${ }^{[7]}$ or conservative managed ${ }^{[8]}$ if superficial up to orbit only, but if CT scan is not available (as in remote areas of developing countries) then only on the basis of plain X-rays and GCS (Glasgow Coma Scale), the patient can be managed to save the life in time.

\section{Case Report}

A 35-year-old male presented in normal sensorium in our emergency room at around $2.00 \mathrm{pm}$ following an accidental injury (fall from height, of about 20 feet) directly on boundary wall's pointed sharp rod [Figure 1] while applying wall putty in daytime at around 12.00 noon. His Glasgow coma score (GCS) was 15, left pupils was normal in size and reacting to light and right pupils was covered with the iron rod that was snugly fit and fixed to orbital roof and basifrontal bone. On local examination, an iron rod with its pointed end was seen entering through

Address for correspondence:

Dr. Vinod Kumar Tewari, 5/279 Vipul Khand, Gomti Nagar, Lucknow - 226 010, Uttar Pradesh, India. E-mail: drvinodtewari@gmail.com 
the bulbar conjunctiva of right superior eyelid towards the skull. No brain matter was seen herniating through it. Immediate $X$-ray (anteroposterior and lateral views Figures 2 and 3 ) revealed the pointed end of the foreign

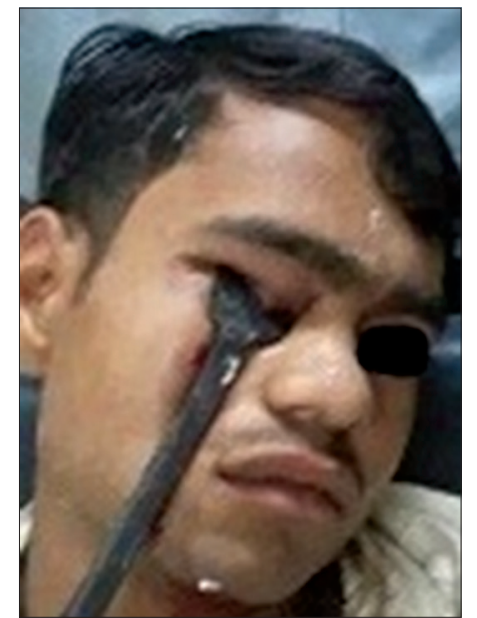

Figure 1: Transorbital orbitocranial penetrating injury, in right eye preoperative

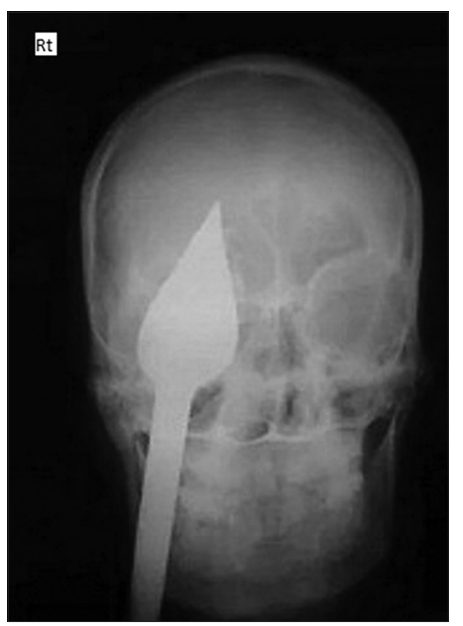

Figure 2: X-ray (AP view)

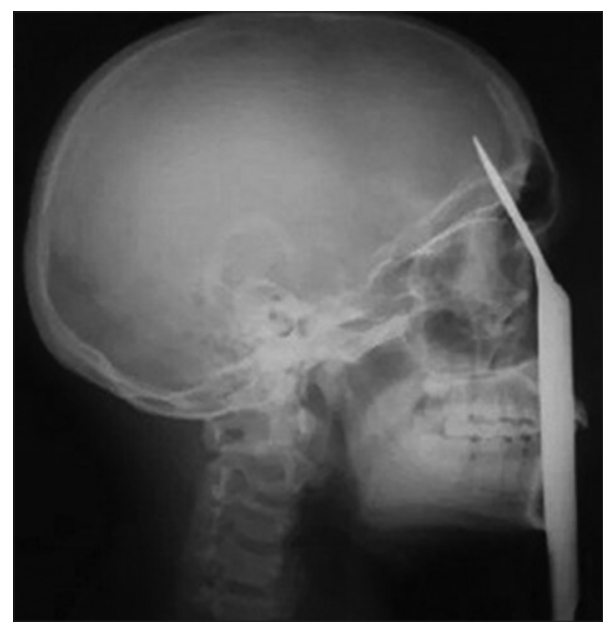

Figure 3: X-ray (lateral view) body (rod) was inside the ipsilateral anterior fossa via basifrontal bone up to frontal vertex, not crossing the midline. He was immediately taken up for emergency operation with multidisciplinary approach, with the help of an ophthalmic surgeon. On peroperative examination, the right ocular globe was intact and the rod has traversed just above the ocular globe, below the upper eyelid piercing bulbar conjunctiva, the roof of orbital fossa, the duramater over the roof, then entering the right basifrontal lobe and touching the dura of the vertex from inside ipsilateral, thus contusing the frontal lobe. Right fronto-temporal craniotomy was raised and duratomy done. Dura was teared from basifrontal region with minute bleeding. The retractor was positioned in such a way that the frontal lobe is retracted only slightly starting from basifrontal extradurally toward medial side and with the assistance of the ophthalmologist the rod was removed from the orbital side gradually by slow zig-zag movements. Contused and necrotic brain tissue with bony fragments was removed carefully. Eyeball was normal. Hemostasis achieved with bipolar and surgicel, dura was repaired at basifrontal and vertex region both with sutures. Closure was done in layers with drainage tube in situ. In immediate postoperative period he was able to count fingers from a distance from right eye, light reflex was present in both the eyes but he was not able to move right eyeball superolateral with profound ptosis. The patient was on broad spectrum antibiotics (intravenous cefoperazone with sulbactam, aminoglycoside, metronidazole and amphotericin B in antimeningitic dosages for 1 week) for gram negative, positive, anaerobic bacteria, protozoan and fungal infections with dehydrants in postoperative period. The patient was discharged on $10^{\text {th }}$ day without any neurological deficit except restricted right eyeball movement to superolateral and ptosis. This restricted eyeball movements recovered after third month of follow up with remnant ptosis for 2 years.

YouTube URL of preoperative and just postoperative phase is:

https://www.youtube.com/watch?feature = player_ embedded \& v=XigEccbTssA

https://www.youtube.com/watch?feature = player embedded \& v=Me5-rWCwKzU.

\section{Discussion}

The most common superficial TOPIs are from metal and glass fragments. They usually cause slight inflammatory reaction within the periorbital fat except copper. ${ }^{[9]}$ But organic foreign body, e.g. wood causes an acute inflammatory reaction, which may become chronic with periorbital abscess, panophthalmitis, meningitis and brain abscess. ${ }^{[9]}$ If these cases are operated with 
appropriate antibiotics then the survival rate improves to $90 \%$ as compared to conservative $38 \% .{ }^{[10]}$ This was because there is a high risk of microbial contamination from wooden foreign body due to their porous consistency. ${ }^{[9,10]}$ The orbital roof is relatively thin part then the rest of skull causes easy access to the projectile objects. Thorough history and clinical evaluation helps in judging local injury to eye-globe and optic nerve. $\mathrm{X}$-ray, CT, magnetic-resonance-imaging (MRI), and ultrasonography, have been advocated for the detection of entry wounds, retained foreign bodies. ${ }^{[9]}$ Foreign bodies made of metal, plastic, or glass, are easily detected with X-ray except wood..$^{[9]}$ CT scan (if available) is excellent for high-density material such as glass or metal but not for low-density objects like wood..$^{[9]}$ Dry wood appears as a linear, circular or oval lucency, similar to air ${ }^{[9]}$ and wet wood is having high density so more difficult to be detected on CT scan, resembles that of the surrounding periorbital fat. ${ }^{[9]}$ MRI detects only in $50 \%$ of cases pre-operatively..$^{[9]}$ The initial treatment of penetrating head injury includes: Aims to save the life by control of persistent bleeding and intracranial hypertension. Surgical management includes debridement of devitalized brain tissue, removal of foreign body, bone fragments, watertight closure of duramater, repair of skull base and closure of scalp. ${ }^{[4]}$ Our study shows that we can start the emergency operation based on stable clinical status (full GCS and normal reacting pupils) and X-rays showing the trajectory of foreign body, not crossing the midline and below the ipsilateral vertex. Also, infections can easily complicate penetrating craniocerebral injuries so we strictly gave higher antibiotics for gram negative, positive, anaerobic bacteria, protozoan and fungal infections to prevent meningitis, epidural abscess, subdural empyema, or brain abscess. Delayed intracranial infective complications include brain abscess, encephalitis, meningitis, osteomyelitis and scalp sepsis and CSF fistula. ${ }^{[9]}$

\section{Conclusion}

This case was operated by a multidisciplinary specialty taking care of orbit and brain before the neurological detoriation could start. CT scan should be in hand to plan more accurately in this case too. Direct visualization and repair of brain structures with higher antibiotics can save the life even in remote areas where CT scan is still not available.

\section{References}

1. Satyarthee GD, Dawar P, Borkar SA, Sharma BS. Trans-orbital penetrating head injury (TOPHI): Short series of two cases with review of literature. Indian J Neurotrauma 2014;11:49-52.

2. Liu WH, Chiang YH, Hsieh CT, Sun JM, Hsia CC. Transorbital penetrating brain injury by branchlet: A rare case. J Emerg Med 2011;41:482-5.

3. Sarma P, Srinivas D, Somanna S. An unusual case of orbito-cranial penetrating injury. Indian J Neurotrauma 2014;11:57-60.

4. Satyarthee GD, Borkar SA, Tripathi AK, Sharma BS. Transorbital penetrating cerebral injury with a ceramic stone: Report of an interesting case. Neurol India 2009;57:331-3.

5. Seex K, Koppel D, Fitzpatrick M, Pyott A. Trans-orbital penetrating head injury with a door key. J Craniomaxillofac Surg 1997;25:353-5.

6. Paiva WS, Monaco B, Prudente M, Soares MS, de Amorim RL, de Andrade AF, et al. Surgical treatment of transorbital penetrating brain injury. Clin Ophthalmol 2010;4:1103-5.

7. Arslan M, Eseoğlu M, Güdü BO, Demir I. Transorbital orbitocranial penetrating injury caused by a metal bar. J Neurosci Rural Pract 2012;3:178-81.

8. Agarwal A, Pratap A, Agarwal CS, Kumar A, Rupakheti S. Transorbital orbitocranial penetrating injury due to bicycle brake handle in a child. Pediatr Neurosurg 2007;43:498-500.

9. Peterson JJ, Bancroft LW, Kransdorf MJ. Wooden foreign bodies: Imaging appearance. AJR Am J Roentgenol 2002;178:557-62.

10. Tite DJ, Batstone MD, Lynham AJ, Monsour FN, Chapman PJ. Penetrating orbital injury with wooden foreign body initially diagnosed as an orbital floor blowout fracture. ANZ J Surg 2002;72:529-30.

How to cite this article: Tewari VK, Dubey RS, Dubey GC. Trans-orbital orbitocranial penetrating injury by pointed iron rod. J Neurosci Rural Pract 2015;6:231-3.

Source of Support: Nil. Conflict of Interest: None declared. 